\title{
Mapping the morphology of urban sprawl and blight: A note on entropy
}

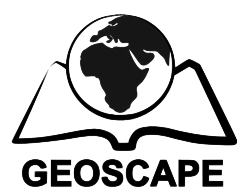

\author{
Reza Banai ${ }^{1 凶}-$ Anzhelika Antipova $^{2}-$ Ehsan Momeni $^{2}$ \\ ${ }^{1}$ Department of City and Regional Planning, University of Memphis, Memphis, U.S.A. \\ ${ }^{2}$ Department of Earth Sciences, University of Memphis, Memphis, U.S.A.

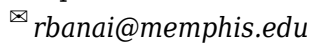

\begin{abstract}
The urban expansion from the city center to the suburb and beyond is indicated by Shannon entropy, a robust and versatile measure of sprawl. However, the metropolitan regionwide entropy masks the morphology of land cover and land use consequential to urban expansion within the city-region. To surmount the limitation, we focus on the block-group, which is a US census defined socio-spatial unit that identifies the metropolitan region's development pattern structurally, forming tracts that comprise neighborhoods. The concentration and dispersion of land use and land cover by block-group reveals a North American metropolitan region's commonly known but rarely measured spatial structure of its urban and suburban sprawl. We use parcel data from county assessor of property (GIS) and land cover pixel data from the National Land Cover Data (NLCD) to compute block-group landuse and land-cover entropy. The change in block group entropy over a decade indicates whether the city- region's land use and land cover transition to a concentrated or dispersed pattern. Furthermore, we test a hypothesis that blight correlates with sprawl. Blight and sprawl are among the key factors that plague the metropolitan region. We determine the correlations with household income as well as (block group) distance from the city center. It turns out, blight is among the universally held distance-decay phenomena. The share of the block group's blighted properties decays (nonlinearly) with distance from the city center.
\end{abstract}

\section{Keywords}

Urban sprawl, Shannon entropy, Simpson diversity, Block group, Urban form, Blight,

Land use,

Land cover,

Spatial census data, GIS

Received:

07 November 2020

Received in revised form: 07 April 2021

Accepted: 22 April 2021

\section{Highlights for public administration, management and planning:}

- The metropolitan region's outward growth is highlighted by mapping the changing morphology of the block group within the city-region.

- The block group entropy is computed with land use (parcel) and land cover (pixel) data.

- The block group entropy change indicates the pattern of the land use and land cover transition with concentration or dispersion.

- We test the hypothesis that blight correlates with sprawl with statistical models.

- The block group's blighted properties decrease (nonlinearly) with distance from the city center.

\section{Introduction}

When the city spreads outward, how does the urban expansion impact the mix and diversity of the land use and land cover within the city and its constituting neighborhoods? What land cover converts to built-up with urban expansion? While sprawl and its consequence blight are generally known as factors that plague the metropolitan re- gion, how might the nexus be calibrated empirically with socio-spatial variables that include a measure of blight as well as sprawl, and thereby verify a hypothesis that blight is correlated with sprawl? We address the research questions with a case of a city in south-eastern region of the US, described later in the paper. First, we note the features of urban sprawl recorded in the literature (subsection 1.1). We briefly review methods used to measure urban sprawl (subsection 1.2). We note how our 
methodology contrasts with those used in the literature (subsection 1.3). We address the questions of land use and land cover structural change with urban expansion, and finally examine the correlations of blight and sprawl.

\subsection{Definitions of urban sprawl}

Urban sprawl is rarely precisely defined (Lopex \& Hynes 2003). However, it is commonly identified by the spread of population and jobs from the city center to the urban and suburban edge, disproportionate consumption of land relative to population, leapfrog development pattern contributing to many current urban and environmental problems including increased vehicle-miles traveled, gridlock on highways and major roads, reduction of green space, and the conversion of green space to impervious land prone to hazardous urban flooding (Nasser \& Overberg 2001; Lopez 2014; Banai \& DePriest 2014). Yet other menacing urban consequences of sprawl include urban or suburban decay, specifically blight identified by abandoned, vacant, dilapidated properties, destruction of community, and income inequality. Social justice research identifies links between urban sprawl and racial segregation, urban poverty, and employment availability (Jargowsky et al. 2011; Ragusett 2016). The impact of blight is experienced concretely when hitting close to home, literally in the neighborhood, rather than conceptualized abstractly in large spans of the urban areas or administrative territories for which sprawl metrics are commonly recorded in the literature (Ross \& Leigh 2000; vom Hofe et al. 2019) (see section 1.1).

Since 2000, urban sprawl characterizes economic development of Memphis, TN (USA), with the region sprawling in bordering counties (Ciscel 2000; Ciscel 2001). A recent study (Ewing \& Hamidi 2014) ranked the Memphis metropolitan region (TN-MSAR) among the most sprawling large metro areas (with a population more than one million) with a score of 70.8; for Shelby County 116.7 and DeSoto County 87.8 , in 2010, even worse than Atlanta's sprawl with a score is 41.0 (Ewing \& Hamidi 2014). The metropolitan region consists of a central city (Memphis) and nine counties that contain several suburban municipalities. Memphis is considered as a mid-size city, however, cities of various size experience sprawl (Gouda et al. 2016).

Next, we briefly review methods used to measure sprawl (subsection 1.2). In our review we note how our methodology contrasts with those recorded in the literature, specifically with the selection of parcels and blocks as spatial units, which affect the calculation of entropy, and application of GIS, which facilitates parcel selection with block groups. We then introduce our case study to address the research questions.

\subsection{A brief review of methods to measure sprawl}

Despite differences in definitions, urban sprawl is measurable. There are numerous methods, from simple to complex, that quantify the wide-ranging dimensions of sprawl. Index methods e.g., "density balance" sprawl index computes metropolitanarea sprawl with geographic census data (Nasser \& Paul 2001; Lopez \& Hynes 2003; Lopez 2014; Galster et al. 2000 provide multivariate indicators of "urbanized area" sprawl. Commonly, the sprawl footprint is mapped at a regional scale, for example city-region, urbanized area, or metropolitan statistical area (Galster et al. 2000; Lopez 2014; Laidley 2016). The urbanized area like the block group is a US census defined spatial unit of the metropolitan region. The aggregate metropolitan-scale measure, however useful for the purposes of comparative assessment of the sprawling metropolitan regions, likely eclipses the different internal urban morphologies that contribute to that sprawl (Ewing \& Hamidi 2014; Laidley 2016).

The block-group constitutes census tracts that approximate the all-important neighborhood scale, a socio-spatial unit uniquely identified in the metropolitan region. Comprehensive, city-wide planning and policy-making with community participation starts at the local, neighborhood level, which provides a fundamental building block of the metropolitan region. The U.S. Census Bureau delineates block groups locally with Participant Statistical Areas Program, PSAP (www.census.gov), yet another indication of the importance of locally-determined measure of the internal structure of the neighborhood as defined by census tracts' block groups that gauge urban sprawl, if any exits. An indicator of sprawl determined at the neighborhood scale aids in that planning. The "neighborhood" connotes multiple meanings and uses (see below Perry's 1929 definition and subsequent modifications with new urbanism, Katz ed. 1994; Duany et al. 2000). However, census tracts which contain block groups are commonly used to represent neighborhoods due to availability of census data, and relative homogeneity of population attributes, economic status, and living conditions. Census tracts are used to study population change, analyze residential housing patterns, and other population-related attributes, while block 
groups represent smaller units of analysis and tend to be more homogeneous compared to census tracts (Iceland \& Steinmetz 2003). Accordingly, measurements of neighborhood attributes may differ based on the selected definition of the term "neighborhood".

The extent to which neighborhood definition may impact the results is akin to modifiable areal unit problem (MAUP) in spatial analysis (Openshaw 1984). For example, studies have found no differences in a residential housing pattern between census tracts and block groups conceptualized as larger and smaller units of neighborhood analysis, respectively (Iceland \& Steinmetz 2003). However, census tract aggregations likely hide the substantial withintract heterogeneity existing among neighborhoods within urban areas (Goodman 1977; Duncan et al. 2017). Cognizant of the potential bias in proximity measures produced by larger administrative, metropolitan area boundaries, we use the smaller unit of analysis - census block groups -for the analysis of urban sprawl (section 2).

In studies of urban sprawl Shannon entropy and Moran statistics are commonly used spatial analytics (for example, Yeh \& Lee 2001; Salvati \& Carducci 2014; Rahman 2016; Musakwa \& van Nieker 2014; Effat \& El Shobaky 2015). The spatial distribution of a geographic phenomenon is measured by entropy (Batty 1972; Thomas 1981). In applications to urban development phenomena, i.e., builtup area commonly with land use and land cover data, entropy measures dispersion and concentration, whereas Moran captures spatial correlation. Normalized, entropy provides a standard metric that determines the magnitude of sprawl in spatial units or zones with different size, with scaleinvariance. Moran index is sensitive to the distance band that determines (or partitions) the weights of the spatial matrices (e.g., see Musakwa \& van Nieker 2014). Entropy generally characterizes a whole system by the proportions of the system elements in concentration and dispersion. This proportional property is particularly useful for an urban system's land use and land cover. The land parcel is a fundamental armature of urbanism. The new urbanism which provides an alternative to sprawl defines the neighborhood not merely by the finer grain of its individual parcels-residential, commercial, open space-but also its mixed land use and density expected within a proportional threshold that promotes walkability (see Calthorpe 1993; Katz ed. 1994; Duany et al. 2000). Similarly, we use the land use parcel data to map block group's land use mix and diversity, regarded among desired features of new urbanism. Furthermore, conceptu- ally urban blocks defined by the homogeneity-order-of the socio-spatial organization noted above, is a logical arena for the application of entropy that captures the magnitude of "disorder" or departure or dispersion from order (see definition in subsection 2.1).

The commonly cited Yeh and Xi's (2001) paper determined the entropy of urban growth by the buffered zones of the expanding periphery with variable density. Yeh and Li (2001) determined entropy of Chinese sprawling cities with land development density of 250-meter buffer zones around city center and roads. In contrast, we determine block-group entropy since we are interested in the question of how urban sprawl impacts within the city and county land use and land cover pattern, as stated at the outset. The within city and county limit scope is particularly helpful for our purpose of determining the impact of sprawl on blight, with inner-city property blight, a consequence of outward urban expansion (Calthorpe \& Fulton 2001; Baum-Snow 2007). The commonly used sprawl metric with a computationally versatile ratio-scale entropy - is rarely investigated in relation to similarly ratio-scaled socio-spatial phenomena. We fill this void through investigation of the connections among entropy (an indicator of sprawl), blight, which is a consequence of sprawl, household income, land use mix, and distance to CBD, which is a commonly used indicator of urban expansion.

Laidley (2016) described measures of sprawl applied by current research and commented on their strengths and weaknesses. The morphological factors used in the computation of a composite measure of sprawl at the aggregate level such as overall density, for example CBD-proximate development, pose a problem of interpretation in the ranking of urban areas receiving high score in some dimensions but scoring low on others suggesting a problem of ranking interpretation. Different urban forms within subareas such as census block groups could produce misleading results (Ewing \& Hamidi 2014; Laidley 2016). Accordingly, the aggregate-level metropolitan scale measure of sprawl likely hides finer differences in urban morphology.

The logic of the block-group as a unit of analysis is the granular scale revealing the spatial structure of city's neighborhoods with metropolitan expansion (subsection 1.3). It is in contradistinction to studies of urban sprawl with a larger, metropolitan-wide, urbanized area, multicounty, and metropolitan statistical area (MSA) (e.g., Masek et al. 2000; Galster et al. 2000; Yeh \& Lee 2001; Laidley 2016). Notable exceptions are Effat and El Shobaky's (2015) entropy map- 
ping of city-district sprawl, and Rahman's (2016a, 2016b) municipal level, and Das and Angadi (2020) sub-regional level. Das and Angadi (2020) use the spatial landscape metrics approach and apply Shannon's entropy model as a sprawl indicator to remotely sensed data at the aggregate scale (towns). Specifically, urban growth was examined by the zoning of each town. Liu et al (2018) used a simplified model to identify the expanding area reflecting urban sprawl patterns as they computed local spatial entropy based on the estimated 2015 population density with a $1 \mathrm{~km} \times 1 \mathrm{~km}$ spatial resolution and applied K-means clustering. Our approach is similar to studies of urban sprawl at municipal level with land use entropy, like Das and Angadi's (2020), but different from existing studies that do not examine the morphology of urban sprawl at a finer-scale of the block group within the city-region or explore the relation of sprawl to blight. Above all else, we stress an entropy analysis of land use pattern at an even a finer-scale of the city-region that is commensurate with neighborhoods that uniquely define the city. A spatial unit of analysis that is used to universally compare cities across the globe is not our intention. For example, Hecht et al. (2019) used a block-level analysis of building pattern, which is of course specific to the place analyzed. However, standard U.S. census designation of a socio-spatial unit that is the building block of the metropolitan region enables comparative assessment of urban sprawl nationally. The versatile ratio-scale of entropy facilitates the comparisons of the spatial concentration or dispersion of land use and land cover pattern even further (section 2).

Urban sprawl is a multidimensional phenomenon. Arguably, no single index captures the complexity of the multiple dimensions of urban sprawl in entirety, as Nazaria et al. (2019) observe. Our focus on the urban expansion's impacts on land use and land cover structural change is arguably one dimension of the complexity of sprawl. Even when limited to land use and land cover, however, we examine other indicators and compare Simpson diversity with Shannon entropy. We identify the multiple dimensions of sprawl at the neighborhood scale as well the related issue of zonal specification also addressed by Nazaria et al. (2019) generally with MAUP in the Discussion and Conclusion section 4.

\subsection{Toward the neighborhood scale: Block groups}

Galster et al. (2000) multifactor indicators of the sprawl of the "urbanized area" include density, continuity, concentration, compactness, cen- trality, nuclearity, diversity, and proximity. Similar multi-attribute urban form features-density, land use mix (diversity), proximity (compactness)-that counter sprawl and thereby promote walkability and accessibility of centrally located urban services, commercial and office with residential land use in proximity appear in new urbanism, new regionalism, and smart growth literature not at the scale of the entire urbanized area but of the neighborhood (Katz ed. 1994; Duany et al. 2000; Calthorpe \& Fulton 2001). The new urbanism refines Perrys' (1929) "neighborhood unit" (Perry 1929), defined by a $1 / 4$ to $1 / 2$ mile pedestrian-shed. New urbanism and smart growth are considered as alternatives to urban sprawl (Katz ed. 1994; Duany et al. 2000; Calthorpe \& Fulton 2001). An index calibrated at the regional scale of the entire car-dependent, urbanized area provides a macroscopic view of urban sprawl but offers little insight about a neighborhood that is defined by the block-group, let alone the quarter-mile, pedestrian-friendly new urbanist or new regionalist neighborhood.

However, the car-dependent neighborhood is a much greater spatial unit than the new urbanism's pedestrian-shed. Similarly, the one-mile grid over a vast, urbanized area less likely reveals the neighborhood spatial structure that is either car-dependent or pedestrian-friendly. The neighborhood is approximated by U.S. defined census tract. Census tracts are commonly used to represent neighborhoods due to their relative homogeneity of the socio-economic and spatial attributes, population, economic status, and living conditions, which are used to study demographic shift, housing patterns, and other population-related phenomena. Block groups represent smaller units and tend to be even more homogeneous compared to census tracts (Iceland \& Steinmetz 2003). Block groups are delineated with local input. A block group is a common spatial and administrative concept in the United States which generally contains between 600 and 3000 people. Since determined with local input, block-group-based neighborhood planning and policy-making likely benefits from local participation and representation that aims to counter undesirable consequences of sprawl (more in discussion section below). Thereby, our block-group index of sprawl with entropy informs neighbourhood planning practice with policy implications.

Rarely studies that account for the metropolitan region's sprawl invoke the neighborhood as a spatial unit with which the variation in both the magnitude and pattern of sprawl is uniquely identified. For example, Yeh and Li (2001) determined entropy 
of Chinese sprawling cities with land development density of 250-meter buffer zones around city center and roads. Galster et al. (2000) determined the sprawl of the metropolitan region's urbanized area with one-mile grid zones. Others employ an even greater spatial extent to map sprawl, for example Masek, et al. (2000) conducted a MSA study of Washington D.C., and Laidley (2016) compared U.S. metropolitan MSA sprawl and related phenomena.

We use land-use and land-cover class, much less unequivocal categorical distinctions of the land class types or subtypes, compared to the fuzziness of the classification of density threshold. Entropy effectively provides a measure of land-use mix, an indicator commonly employed in studies of sprawl. Land-use mix that indicates inherently different types of parcels in a concentrated or dispersed pattern is concomitant with the conceptual definition of the entropy of a system that exhibits order, or departure from order (recall definition of census block attributes noted above).

Like studies that use land cover data to determine spatial structure of urban development with $\mathrm{Na}$ tional Land Cover Data (NLCD) (e.g., Bereitschaft \& Debbage 2014), we use seven land cover types with developed (built-up) and non-developed land (2011). Arguably, the spatial structure of land cover types is consequential for the neighborhood, revealing sprawl, if any exists. The block-group approximates that spatial structure at a higher resolution compared to the metropolitan-wide pattern of land cover. We use the change in entropy to determine block-group land cover transitions (process) overtime (2001-2011). Our measure of land cover entropy characterizes the mosaic of block-group transitions, with concentration or dispersion. We then focus on the conversion of vacant to built-up land (2010) to determine block-group entropy (state). Thereby, we account for both process and state in mapping urban sprawl (e.g. Bourne 2001).

Furthermore, studies that use entropy to measure the growth and sprawl of the metropolitan regions rarely examine sprawl-related phenomena, the versatile (ratio-scale, normalized) property of entropy notwithstanding. In this paper we examine the correlation of sprawl and blight (see also Calthorpe \& Fulton 2001). Similar to studies that account for the impact of spatial proximity in measurement of sprawl (Baum-Snow 2007), we measure the blockgroup distance to the city center and examine the hypothesis that blight decays with distance from the city center. Galster et al.(2000) use an approach based on a combination of GIS and field surveys. Lopez and Hynes (2003) note a sprawl index that is threshold-level sensitive, with context-dependent, multivariate indicators, for example density, poses a limitation particularly in comparative calibration and evaluation of sprawl across metropolitan areas. Methods that use the standard census definition of metropolitan subareas, e.g. block group with readily available socio-spatial attribute data, e.g., population and housing units, land use in lieu of cumbersome field survey to compute a sprawl index are considered advantageously (Nasser \& Paul 2001;Lopez \& Hynes 2003).

We use census-defined block groups as areal units that approximate metropolitan region's neighborhood spatial extent and a robust index (entropy) that offers a similar advantage of readily retrievable spatial (census) data in the absence of direct survey. Furthermore, we determine block-group sprawl granularly, with parcel data, also available in public domain GIS (county tax assessor of property). Arguably, the parcel is not subject to the ambiguity of the classification (i.e. residential, commercial, open space) compared with the threshold of density which is not regarded unequivocally categorically throughout the metropolitan region even when ratio-scaled, e.g. floor-area-ratio (FAR), or the number of dwelling or population per unit of area (hectare) When proximity to urban center(s) is used as an indicator of sprawl, overlooked is the variation of in land-use mix which occurs at various proximities to center(s). In contrast, we account for the variation in land-use mix by block group distance to the center. Others highlight structural factors that contribute to sprawl by making a distinction between process (cause) and state (effect). For example, Bourne (2001) notes population cohort as a key structural factor in the dynamics of urbanization or suburbanization. While the disproportionate use of land relative to population is an indicator of sprawl, the process of urban development is characterized by the spatial structure of conversion of unused land and greenfield to built-up.

With a land use and commuting model, BaumSnow (2007) shows the structural effect of highway on suburbanization of population. Inner city's population is decreased with a new highway passing through the center. Thus, the distance that the population is located from the central part of the city is considered as an indicator of sprawl (more on the distance-effect below). Like studies that account for the impact of spatial proximity and centrality in measurement of sprawl (Galster et al. 2001, Baum-Snow 2007), we use the block-group distance to the city center and examine the hypothesis that blight decays with distance to CBD. Similar 
to studies that uncover the dimensions of sprawl, and relate it to other outcomes, for example, transit accessibility, public health, energy use, air quality (Ewing et al. 2003; Clark 2013), we measure the correlations of sprawl, blight, income, and block-group distance to city center by using a robust index of entropy.

\subsection{A Case study of sprawl: Memphis and Shelby County}

We focus on Memphis and Shelby County, located in the southeastern U.S. region that is commonly known for urban sprawl. However, the variation in magnitude of that sprawl within the metropolitan region is rarely measured, while the overall metropolitan area sprawl value may mask substantial variation across geographic areas of various degree of urbanicity, urban and suburban. The distribution of block groups' entropy values shows the differentiation of the block groups' urban pattern from the city to the county. As well, we compute the change in entropy values over a period of a decade that indicate whether the urban pattern from the block to the regional scale resembles more or less sprawl. We compute the entropy index for both land use and land cover. The decade-worth of the transitions in the seven land cover types shed additional light on the pattern of sprawl and the consumption of land, particularly from greenfields to built-up areas. We determine Shannon entropy for both land use and land cover at the block-group level (subsection 2.1). Our central city and county block-level focus is thus more granular and thereby differs from studies of urban sprawl with a larger, metropolitan-wide, multi-county, metropolitan statistical area (MSA) or "urbanized area" (e.g., Masek et al. 2000, Galster et al. 2000). The finer-grain, blockgroup areal focus aims to approximate the allimportant neighborhood scale, and thereby facilitates investigations of a wide variety of phenomena with readily available census block data. Furthermore, entropy commonly used to measure sprawl is rarely related to other urban spatial structural phenomena, with notable exceptions (e.g. Laidley 2016). We fill this void and test a hypothesis that block-group sprawl correlates with blight. Blight and sprawl are among the key indicators that plague the metropolitan region, also called "twin problems" of the regional city (Calthorpe \& Fulton 2001; Mock 2017).

Furthermore, we map land-use diversity, which is a factor in a definition of sprawl, e.g., Galster et al. (2000), as well as sprawl (dispersion or concentration) by using Simpson and Shannon indices, respectively (Morris et al. 2014; Yeh \& Li 2001). Rarely the two indices are examined sideby-side, reflecting both the concentration or dispersion (Shannon) and diversity (Simpson) in the measure of the magnitude and land-use pattern of urban sprawl (see also Bhatta et al. 2010).

There is a large number of parcels in our case study city and county. We use GIS to aggregate parcels by block groups. Our GIS-aided mapping of the morphology of land use and land cover by block group reveals the manifestation of urban expansion with distance from the city center. We set out to capture the differentiation of the block groups' land use and land cover pattern from the city to the county. As well, we determine how the urban block group pattern metamorphoses to more or less sprawl over a period of a decade of expansion. The decade-worth of the transitions in the seven-land use and land cover types shed additional light on the pattern of sprawl and the consumption of land, particularly from greenfields to built-up areas. Built-up area includes all uses of developed area including all impervious areas, roads and airport while excluded are planted/agricultural lands, forests, wetlands and water bodies, shrublands, herbaceous and barren and any unused lands. Built-up area is expressed as a proportion of all land cover with 2001 and 2011 data (Multi-Resolution Land Characteristics Consortium (MRLC); https://www.mrlc.gov). Land use classification is from county assessor parcel GIS data including residential, commercial, public (exempt), mixed-use, industrial, and farming/agricultural. We determine entropy for both land use and land cover at the block-group level (subsection 2.1). The justification for the entropy-based method used to gauge sprawl at the block-group scale is provided next (subsection 1.1).

We use geographic information systems (GIS) parcel data from county assessor of property, and a thirtymeter resolution raster map from the National Land Cover Data (NLCD) to map and compute block-group entropy of land use and land cover, respectively. We determine the correlations of blight and sprawl with statistical models that include household income as well as block distance from city center. It turns out, the universallyheld distance-decay phenomena include blight. The share of blighted properties in the census block group decays exponentially with distance from the city center. We observe a correlation of blight and sprawl. The steps of the procedures to address the research questions stated at the outset are represented with the following decision-tree (Fig. 1) 


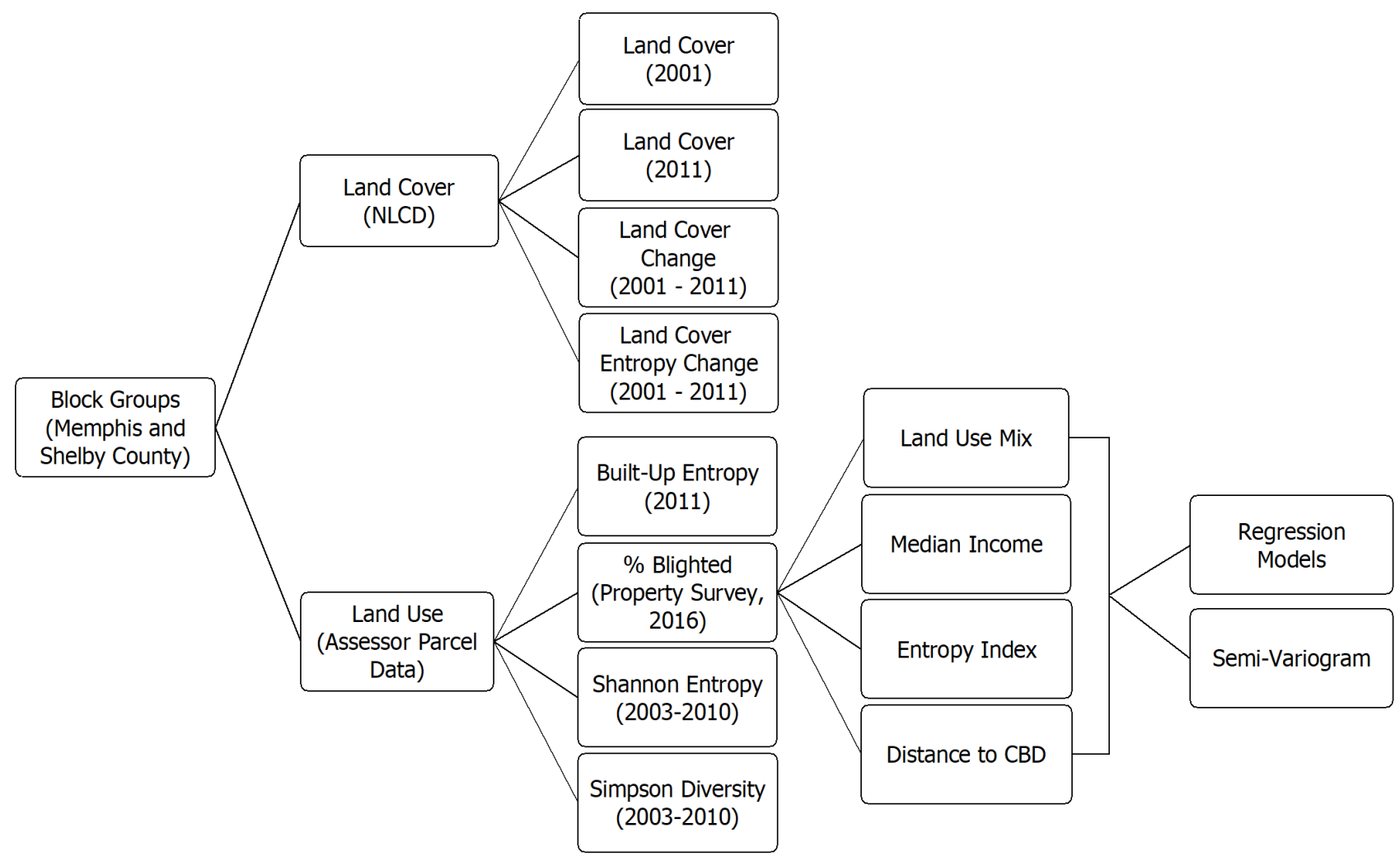

Fig. 1 A decision tree for mapping block group sprawl and blight

\section{Mapping the morphology of urban sprawl and blight}

\subsection{Shannon Entropy}

According to information theory, high entropy is the most probable, yet least predictable, state that leads to disorder (Theil 1967; Thomas 1981). Entropy is used to gauge urban sprawl (Yeh \& Li 2001; Bhatta et al. 2010; Tewolde \& Cabral 2011), a phenomenon laden with "disorder" and the challenges of "predictability."

We use Shannon's entropy to quantify the degree of dispersion or concentration of built-up area using both land use and land cover data, a manifestation of urban development phenomena. Higher entropy values that are observed when there is a continuous dispersion of built-up indicate trends of urban sprawl while lower values which characterize concentrated or less fragmented built-up area, thus further occurrence of build-up is less likely. Shannon's entropy is calculated thus:

$$
H_{j}=\sum_{i}^{s} p_{i} \log _{e}\left(\frac{1}{p_{i}}\right)
$$

where $p_{i}$ is the probability or proportion of occurrence of ith phenomenon (or variable) in the $j$ the spatial unit (zone) among $J$ (total) spatial units (or zones), $s$ is the total number of phenomena or (variables), the probability, thus, is given by:

$$
p_{i}=\frac{x_{i}}{\sum_{i}^{s} x_{i}}
$$

where $x_{i}$ is the observed value of the ith phenomenon (or variable) in the $j$ th spatial unit (or zone) (Roth et al. 1994; Plexida et al. 2012).

Our phenomena are the various land uses or land covers. We have six land use types $(s=6)$, for example, residential, commercial, institutional. There are eight land cover types ( $s=8)$, for example, developed, forest, water bodies (the description of land cover types is given in Table 1 . We have a total of 656 block groups in the county $(J=656)$. To calculate $p_{i}$ we devided the area of ith variable (e.g. residential) to the total area of the block group. pi is defined by the share of each land use or land cover $p_{i}$ of the spatial unit. $p_{i}=0$ when the land use or land cover is not present in the spatial unit. For example, there is no residential among other land use types in a zone.

Entropy values range between 0 and $\log (s)$, indicating concentrated and dispersed patterns, respectively. It is desirable to normalize entropy $\mathrm{H}_{\mathrm{j}}$ so that 
Table 1 Land cover change in Memphis and Shelby County from 2001 to 2011

\begin{tabular}{|c|c|c|c|c|c|c|c|c|c|c|}
\hline \multicolumn{2}{|c|}{$\begin{array}{l}\text { Land cover change } \\
\text { (percent) }\end{array}$} & Developed & Barren & Forest & Herbaceous & $\begin{array}{l}2011 \\
\text { Planted/ } \\
\text { Cultivated }\end{array}$ & Shrub & Water & Wetland & sum \\
\hline \multirow{9}{*}{ 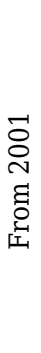 } & Developed & 40.899 & 0 & 0 & 0 & 0 & 0 & 0 & 0 & 40.899 \\
\hline & Barren & 0.06 & 0.142 & 0 & 0.001 & 0.001 & 0 & 0.006 & 0 & 0.209 \\
\hline & Forest & 0.736 & 0.027 & 12.609 & 0.077 & 0.025 & 0.056 & 0.003 & 0.007 & 13.539 \\
\hline & Herbaceous & 0.004 & 0.001 & 0.003 & 0.055 & 0 & 0 & 0 & 0.001 & 0.063 \\
\hline & Planted/Cultivated & 2.065 & 0.033 & 0.044 & 0.01 & 23.835 & 0.044 & 0.053 & 0.093 & 26.178 \\
\hline & Shrub & 0.292 & 0.02 & 0.039 & 0.017 & 0.01 & 4.574 & 0.003 & 0.008 & 4.963 \\
\hline & Water & 0.048 & 0.049 & 0.001 & 0.002 & 0.006 & 0.016 & 4.565 & 0.023 & 4.711 \\
\hline & Wetland & 0.185 & 0.004 & 0.001 & 0.003 & 0.002 & 0.002 & 0.009 & 9.233 & 9.438 \\
\hline & sum & 44.288 & 0.276 & 12.698 & 0.164 & 23.878 & 4.692 & 4.638 & 9.365 & 100 \\
\hline
\end{tabular}

its value is bounded by 0 and 1 , with relative entropy $H^{\prime}{ }_{j}$ (Roth et al. 1994; Plexida et al. 2012).

$$
H_{j}^{\prime}=\frac{H_{n j}}{\log _{e}(s)}
$$

Thus, $0 \leq \mathrm{H}^{\prime}{ }_{\mathrm{j}} \leq 1$. Applied to land cover and land use, the range of entropy values from 0 to 1 effectively connotes less to more "mix" of land cover and or land use, or, alternatively, from "coarse grain" to "fine grain," respectively. Thus, the relative entropy value $\mathrm{H}_{\mathrm{j}}$ is regarded as an indicator of the urban form of the metropolitan region and its subareas. Entropy values monitored over years provide a quantifiable description of the extent of the dynamics of the transformation of urban form to policy makers.

The change in entropy over time $(t)$ over period $m$ is given as follows:

$$
\Delta H_{j}^{\prime}=H_{j}^{\prime}(t+m)-H_{j}^{\prime}(t)
$$

We compute the change in entropy values over a decade $(m)$, from 2001 to 2011 (for land cover) and from 2003 to 2010 (for land use), to determine whether the block groups transition to a more or less concentration or dispersion of land cover and land use pattern.

\subsection{Block-Group land cover and land use transitions}

We used eight categories of land cover (see also Fig. 2). Land-cover categories included developed, barren, forest, herbaceous, planted/cultivated, shrub, water, and wetland. We also used six-land use categories (residential, commercial, exempt public, mixed-use, industrial, farming/agricultural. The National Land Cover Data (NLCD) http://www.mrlc.gov/ is the source of time series (2001 and 2011) land cover data, and county tax as- sessor parcel GIS data is the source of 2010 land use classification. Assessor GIS data are georeferenced shapefiles of parcels. City and county block group boundaries come from Census TIGER (NHGIS).

The land-use entropy for the built-up areas of Memphis and Shelby County by block group (2010) is shown in Fig. 3. Measured by Shannon relative land use index, low entropy values indicate low land use mix (less mix and thus, more concentration, less fragmentation) commonly observed in areas where a single land use type dominates, such as a regional park (e.g., Shelby Farms Park), shown to the east of interstate highway (I-240 loop) in the thematic map whose entropy index value is < 0.2 . To compare, the block group's median entropy of built-up areas for 2010 is 0.73 , which confirms our expectation of urban sprawl. It turns out, builtup areas have become more spread out in 2010, compared to 2003, with an entropy median value of 0.62. Similarly, entropy is computed for land cover types to examine the fragmentation/concentration of the land cover pattern. For the eight land cover categories, the median, 0.07 , is slightly lower in 2011 than in 2001, which is 0.08. Stated differently, block groups' built-up areas have become more spread out, from 2003 to 2010, while their land cover have become slightly less fragmented, from 2001 to 2011.

We show land cover transitions overtime (2001-2011) by the change in Shannon land cover entropy using equation (4) (Fig. 4). As well, we show the transitions of the land cover by type, and highlight the built-up shares of the transitions (Table 1). The regional park has a slight transitional value shown in legend (0-0.1), which indicates that its dominant land cover-green space-has changed very little from 2001 to 2011, as expected due to the planned conservation regulation (Fig. 4) [Its land cover diversity index value, which is defined further below, is also less than 0.2.] 


\section{sciendo}

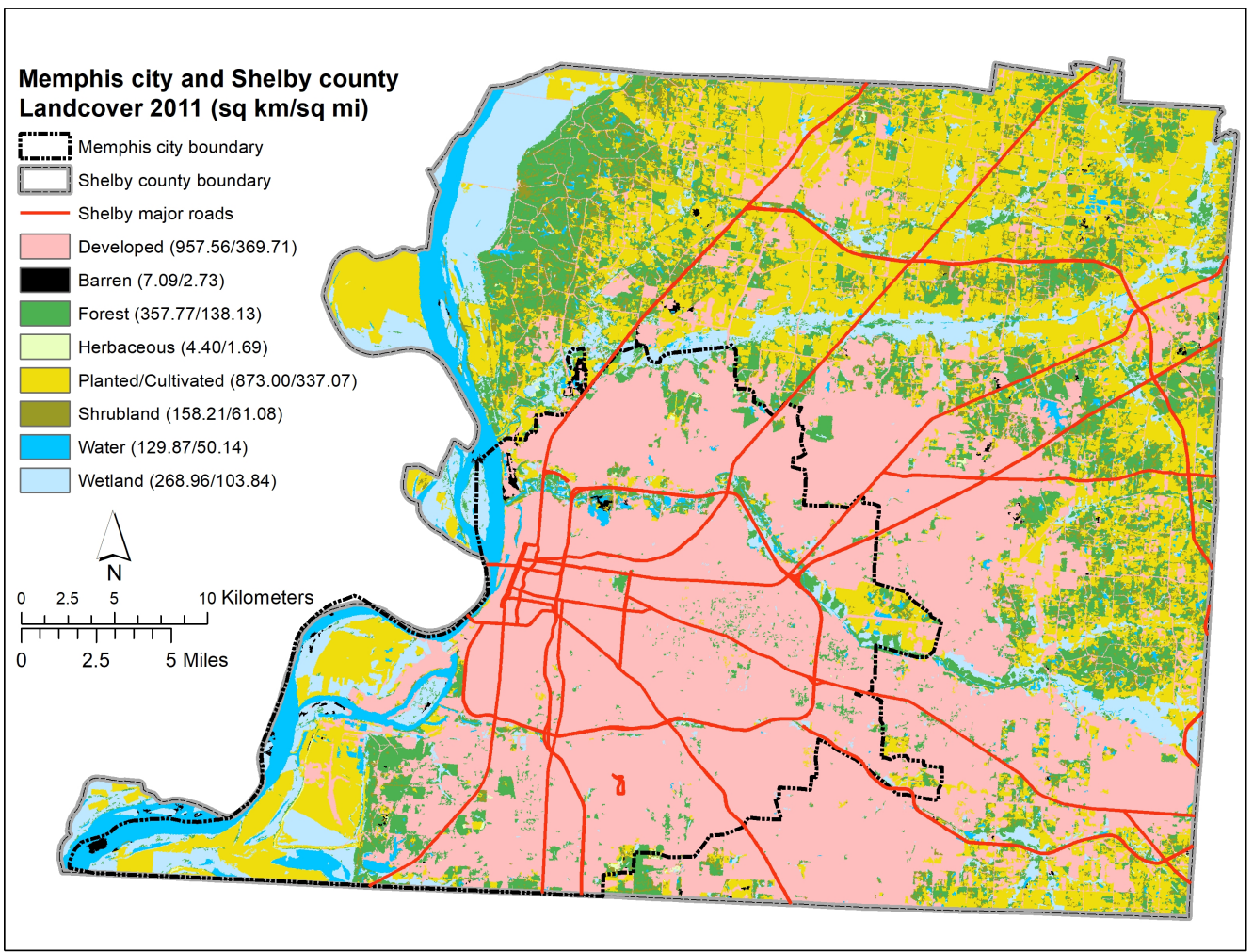

Fig. 2 Memphis and Shelby County Land Cover, 2011 (Source of land cover data, NLCD)

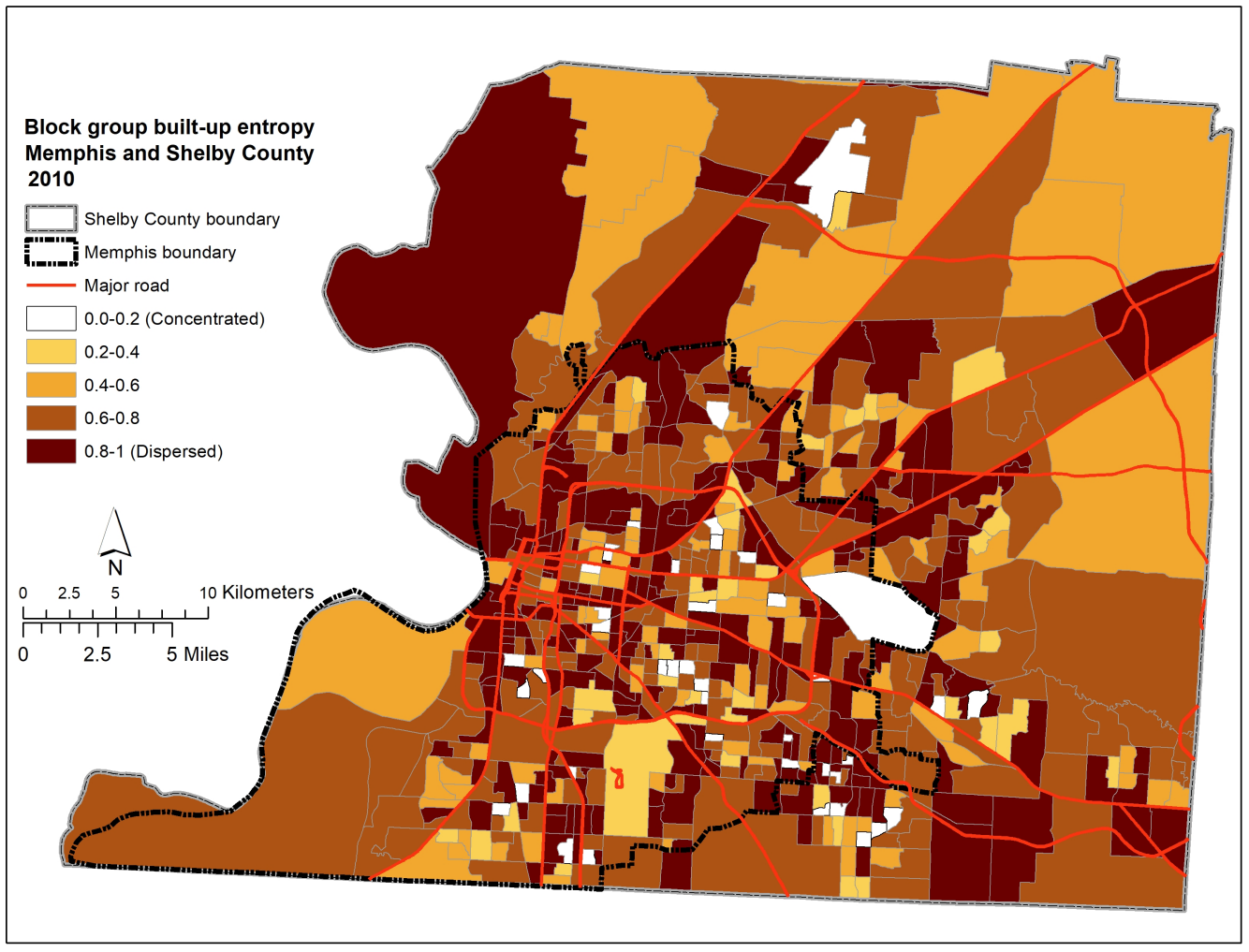

Fig. 3 Block group built-up entropy (Shannon relative index for land use), Memphis and Shelby County, 2010. Source of GIS parcel data, county assessor of property 


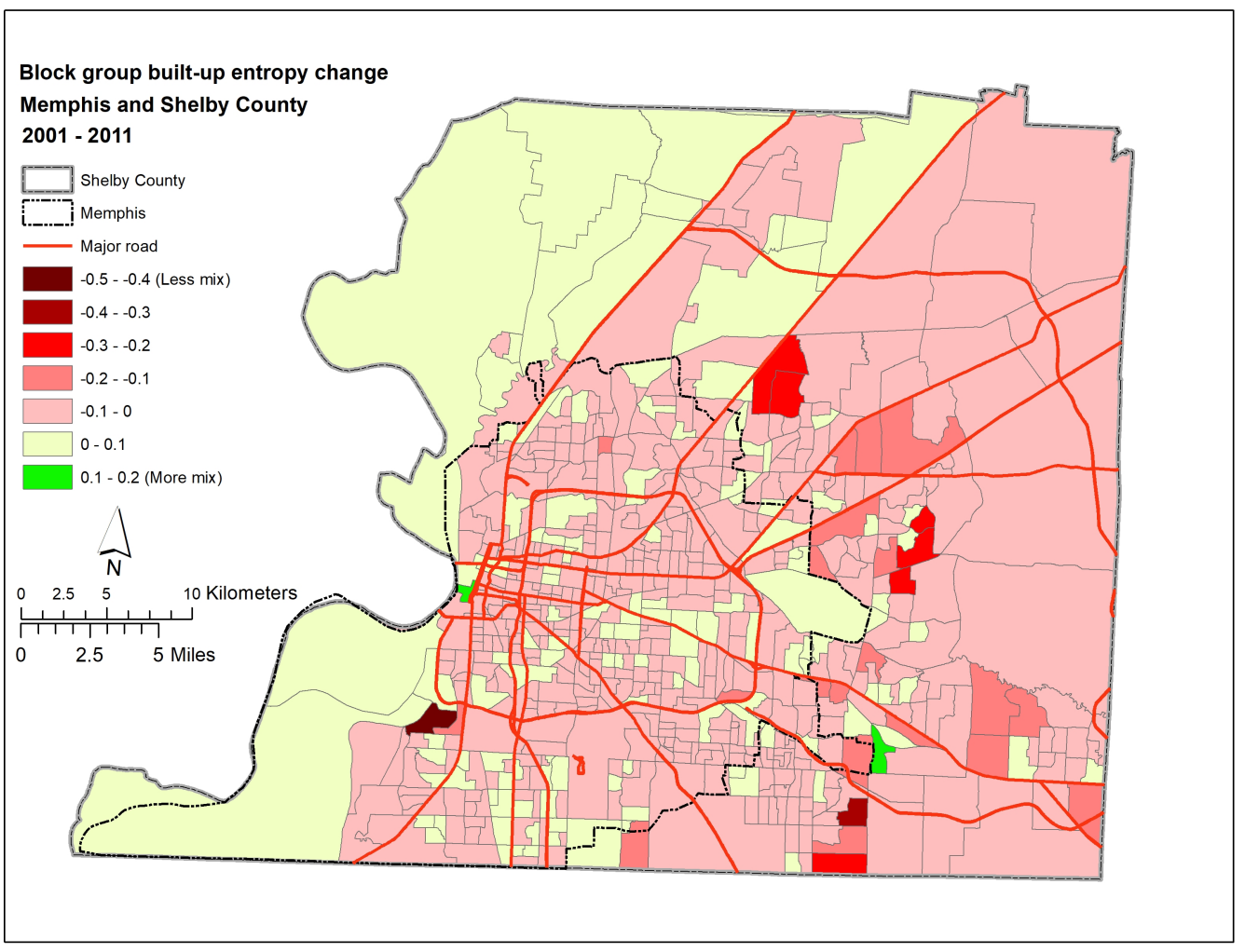

Fig. 4 Built-up transition in Memphis and Shelby County indicated by block group entropy change (Shannon relative), 2001 to 2011

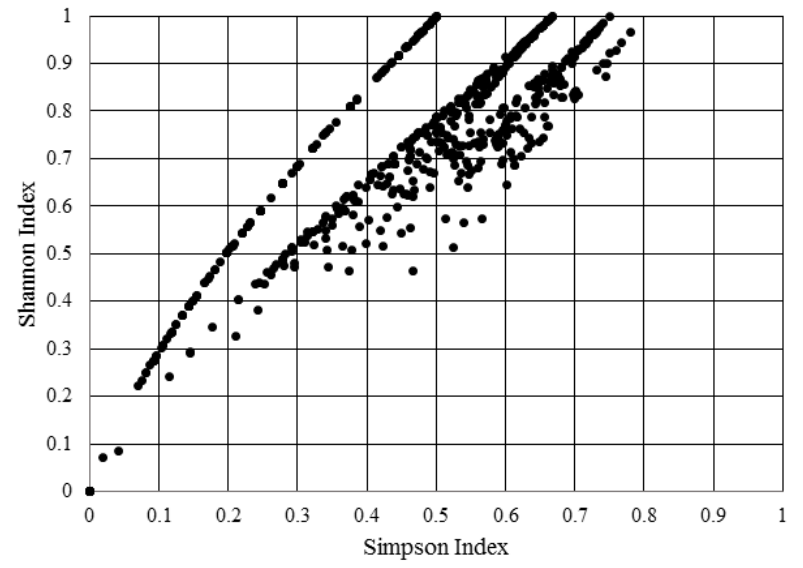

Fig. 5 Simpson vs. Shannon relative index at built-up areas of Memphis and Shelby County, 2010

The suburban and exurban expansion of the City of Memphis into the greenfield sites of Shelby County and beyond is commonly known, but rarely measured. Our mapping shows the extent of land cover conversions for the period from 2001-2011. It turns out, "planted/cultivated" is the largest pro- portion of land converted to "developed" or built-up land. Adding other non-developed areas including forest, shrub land, herbaceous, and even wetland and water (0.64), yields the proportion of "nature" to urban development of $1.74 \%$. For city and county combined, planted/cultivated, and forest represent the largest proportion of the transition from nature to urban development. The significance of this value is realized as a proportion of total land area of the city and county.

\subsection{Simpson Diversity Index}

As well as a decade of transitions in the land cover in the city and the county (Fig. 2), we focused on the built-up or developed land and the transitions over a decade. Simpson's diversity index, based on the probability that any two elements selected at random will belong to the same category, is another measure of diversity ranging between 0 and 1 , with low values of $\mathrm{D}$ implying a lack of diversity and high values corresponding to better diversity (see also Bhatta et al. 2010). To determine if the built-up or developed land, measured by Shannon land cover entropy, is a random pattern that is 
more or less diverse in land use we used Simpson's diversity index $D$, defined thus:

$$
D=1-\sum_{i}^{s} p_{i}^{2}
$$

where $p_{i}$ is the proportion of a land use category, as in the equation 2 above. The power in $p_{i}^{2}$ signifies sensitivity by using arithmetic mean (see Tuomisto 2010).

It turns out that the entropy (relative Shannon) index of sprawl and Simpson's index of diversity of built-up land increase in tandem: the builtup that approximates sprawl, i.e., close to entropy value of 1 is increasingly more diverse, close to the Simpson's index value of 1 (Fig. 4). For example, the regional public park (Shelby Farms Park), shown to the east of interstate highway (I-240 loop) in the thematic map (Fig. 5) of land cover transitions with entropy index value change $<0.2$ has a similar diversity index value, since park/open space is the predominant land use.

For the city and county land use as a whole, in 2010, the distribution of Simpson's and Shannon in the highest value range (0.75-1.00) indicates significant sprawl compared to diversity (Fig. 6a). However, for index values less than 0.75 , while both sprawl and diversity are evident, land-use diversity is more frequent compared to sprawl. Looking at the Simpson's index of land-use change from 2003-2010 (Fig. 6b), the distribution of land use diversity is similar to the index value of less than 0.5 ; however, for index values greater than 0.5 , diversity is lower for the year 2010, compared to 2003. Fig. 6c sheds some light on the transitions with marked shift to sprawl from 2003 to 2010 with Shannon index value in the highest range, greater than 0.75 .

\section{Correlation of sprawl and blight}

A vast array of literature documents the wideranging, and menacing social, economic, and environmental consequences of sprawl, including, but not limited to, regional (income) inequality, diminishing regional mobility and accessibility to jobs and services, increasing public health consequences of limited walkability (physical inactivity, obesity) of an auto-centric urban form, increasing demand on city services and infrastructure outpacing ability of local government to supply services (e.g., see Hasse \& Lathrop 2003; Papas et al. 2007). Calthorpe and Fulton (2001) argue that sprawl is systemically correlated with income inequality, also called the "twin problems" of the regional city. For further theoretical and method- ological review and discussion of the connection of sprawl and blight, see Babcock (2008), Brueckner and Helsley (2011), and Hortas-Rico (2015).

However, inadequate empirical attention is given to urban blight particularly when using entropy as a measure of sprawl. Blight and sprawl are among key factors that plague the metropolitan region. However, in discussions of sprawl and blight, inadequate attention is given to how the two phenomena are correlated. We set out to determine a measure of the relationship.

We focus again on the block-group (Fig. 7). The census block groups constitute census tracts that approximate the neighborhood. A wealth of (census) block-level socio-economic and spatial data facilitates an empirical test of a hypothesis that blockgroup sprawl correlates with blight. We use parcel (GIS) data from county assessor of property to map and compute block group-level entropy index using land use types and determine the correlations of blight (measured as a percent blighted properties per block group) and land use mix (Shannon entropy index for land uses) with regression models that include household income as well as block group distance from the city center. GIS facilitated the computation of Shannon entropy index at the blockgroup level from a large number of county parcel data.

In Model 1, we investigate a relationship between blight and land use mix, measured by Shannon relative index, see equation (3). We used the OLS regression method. Residuals have been tested for the first order autocorrelation of the independence assumption with the Durbin-Watson statistic which for the present case of our dependent variable (percent blighted) was close to 2. Residuals are assumed to be independent, and any pattern in the residuals such as clustering indicates that some of the key explanatory variables are missing from the model. Residual spatial autocorrelation reduces the precision of OLS estimates, specifically resulting in underestimation of the standard error and indicating explanatory variables significant when they are not. In our case. observations are made over time, increasing the likelihood that successive observations are related (known as first order autocorrelation). To test that residuals are uncorrelated with each other, we applied the Durbin-Watson statistic (Barker \& Shaw 2015). The statistic tests for this specific condition of the first order autocorrelation, that is, that there is no autocorrelation in residuals over successive time intervals. The value of the DW close to 2 suggests that the error terms are independent (Field 2009). 

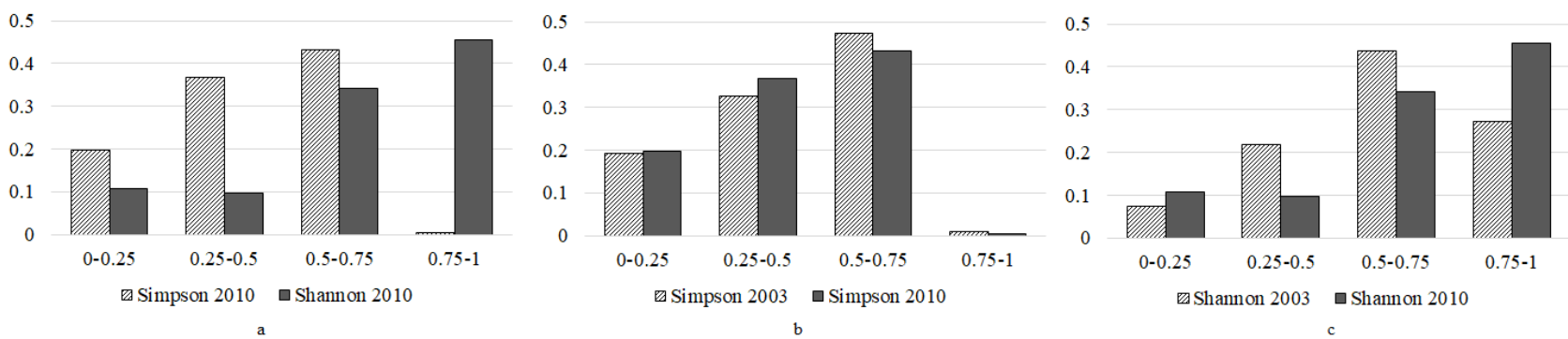

Fig. 6 (a) Distribution of Simpson (diversity) and Shannon (sprawl) index of land use for Memphis and Shelby County, 2010; (b) Simpson index 2003-2010, and (c) Shannon index, 2003-2010.

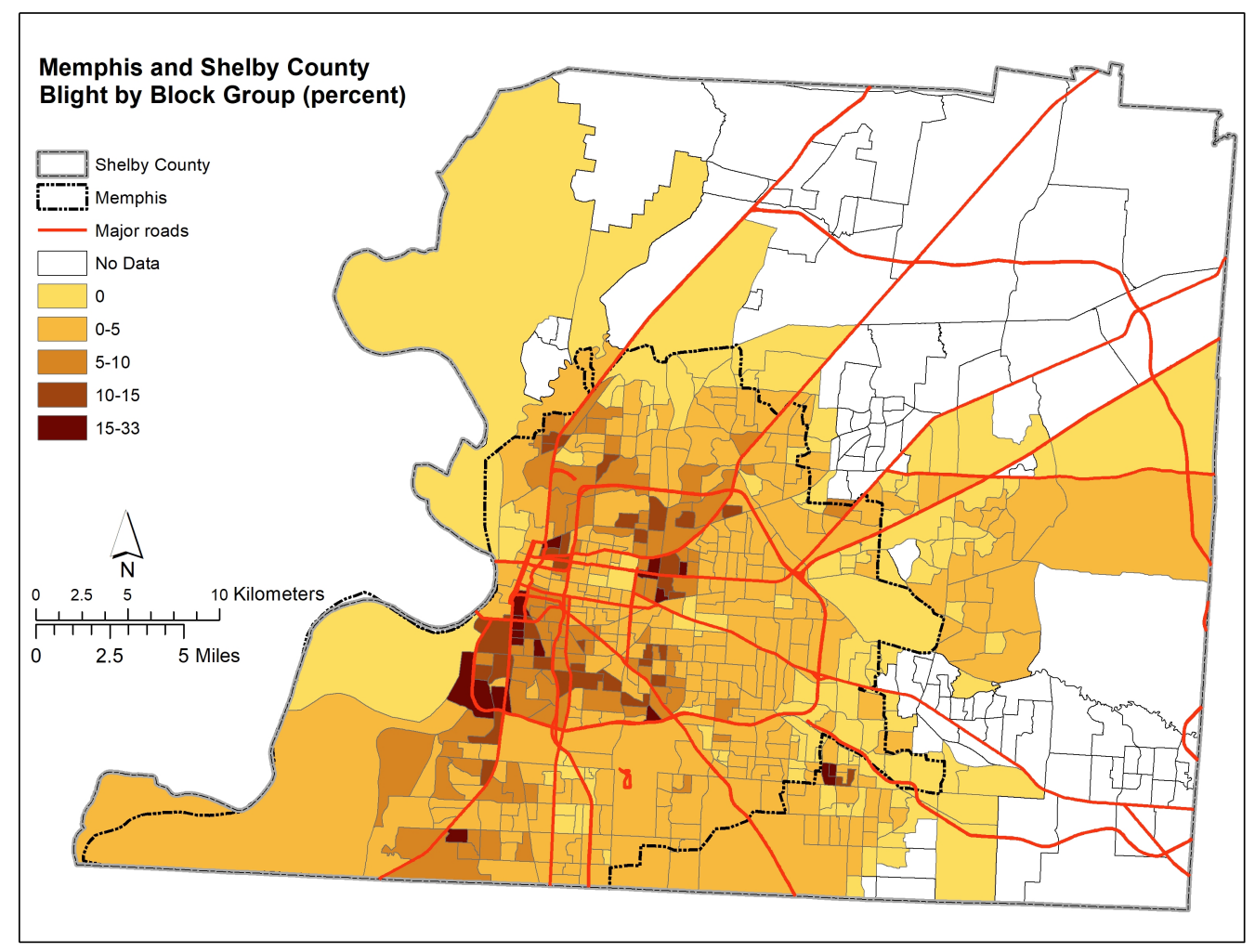

Fig. 7 Distribution of blighted area by block group in Memphis and Shelby County, 2016. (Source of property blight data: Bluff City Snapshot survey, 2016)

Recall, our hypothesis states that blight correlates with on sprawl. However, there are a number of explanatory variables that elucidate the connection of blight and sprawl noted above. We use income to account for regional inequality, a fundamental manifestation of sprawl (Calthorpe \& Fulton 2000), and distance to city center, which reflects the outward growth of the city (Baum-Snow 2007).

We applied a regression analysis to examine the form of the relationship between Shannon relative index, as an independent variable $\mathrm{x}$ and blighted area percentage as a dependent variable for block groups in Memphis and Shelby
County for 2016. We got a better model fit by fitting a log-linear function in a regression equation. The log-log regression specification is in the form:

$$
\log _{e}(y)=\beta 0+\beta 1 \log _{e}(x 1)+e
$$

Solving for $\mathrm{y}$ :

$$
y=e^{\beta 0+\beta 1 \log _{e}(x 1)+e}
$$

To get the marginal effect we need to differentiate with respect to $\mathrm{x}$ :

$$
\frac{d y}{d x_{1}}=\beta_{1} \frac{y}{x_{1}}
$$


Solving for $\beta_{1}$ (which is an elasticity) we get:

$$
\beta_{1}=\frac{d y}{d x_{1}} \frac{x_{1}}{y}
$$

Applying the Model 1 regression results (equation $6)$, the equation we obtained was as follows:

$$
\text { prcblight }=e^{-3.62+1.003 \cdot \log _{e}(\text { ShannonIndex })+e}
$$

The estimated $\beta_{1}=1.003$, it means that a $10 \%$ increase in the value of the Shannon index (more mixed land uses) would lead to a $10 \%$ increase in percent of the blighted area within a Census block group. We observed a greater blight within the urban inner area where there is a greater land use mix which decrease with the distance from the CBD towards the peripheral suburban areas.

Various independent variables were added to the model, separately and combined, to explore the relationship between Shannon entropy, income and distance to the CBD and blight. Fig. 8 illustrates the fitted plots of predicted variable (prcblight) and independent predictors in bivariate regressions (shannon index, medinc, and cbdmet).

We used alternative measures of income as an indicator of inequality in a statistical investigation of sprawl and blight in Model 2 (equation 11). With per capita income $\mathrm{x}$ we find the best log-linear fit (Fig. 8b):

$$
\text { prcblight }=e^{13.02-1.7 \cdot \log _{e}(\text { median income })+e}
$$

$(\mathrm{F}=184.48 ; \mathrm{R}$-Square $=0.31 ; \mathrm{RMSE}=1.16 ; \mathrm{N}=627)$ In Model 2 ( equation 11), the estimated $\beta_{1}=$ -1.7 , it means that a $10 \%$ increase in median income would lead to a $17 \%$ decrease in percent of the blighted area within a Census block group. Blighted area can be mostly found within census block groups in the central area of the city which are often abandoned property.

Next, we used the following rationale in the examination of the link between blight and land use mix reflected in distance to city center (CBD) (Model 3 ). We observe that the incidence of blight measured by proportion of blighted properties per census block group y decreases log-linearly with distance $\mathrm{x}$ from the city core (7(c)).

$$
\text { prcblight }=e^{4.44-0.911) \cdot \log _{e}(C B D \text { distance })+e}
$$

$(\mathrm{F}=86.24 ; \mathrm{R}-\mathrm{Square}=0.17 ; \mathrm{RMSE}=1.27 ; \mathrm{N}=627)$
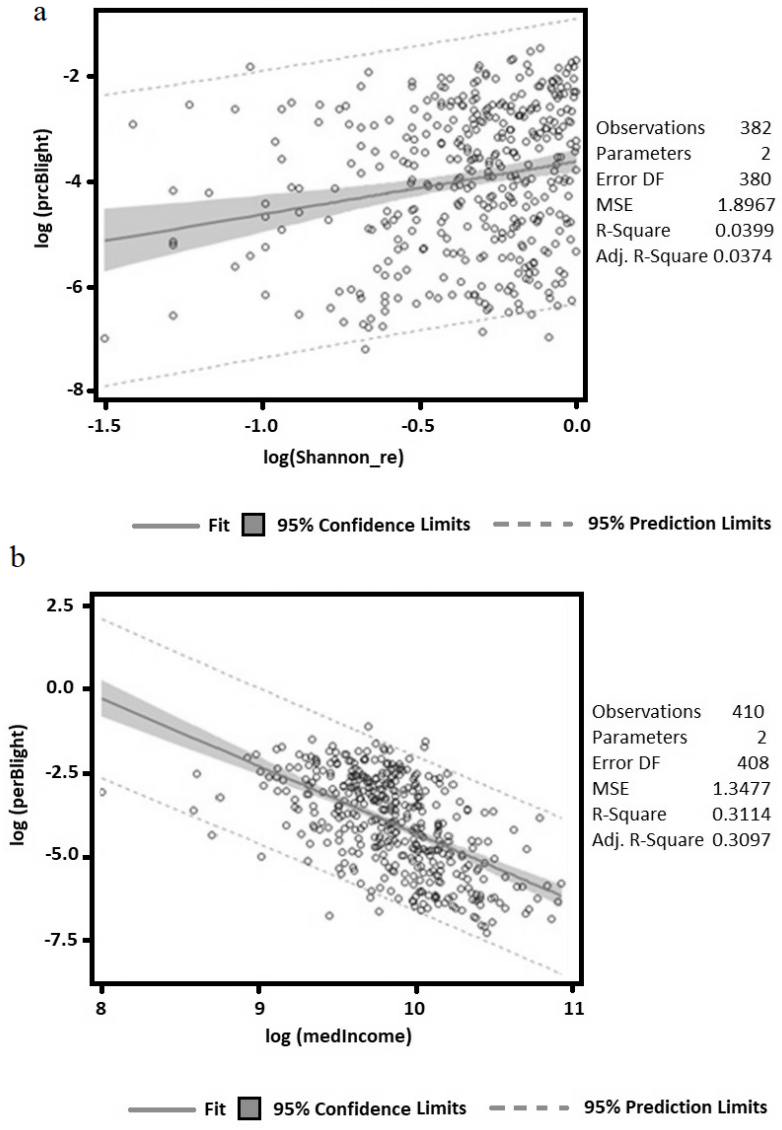

c

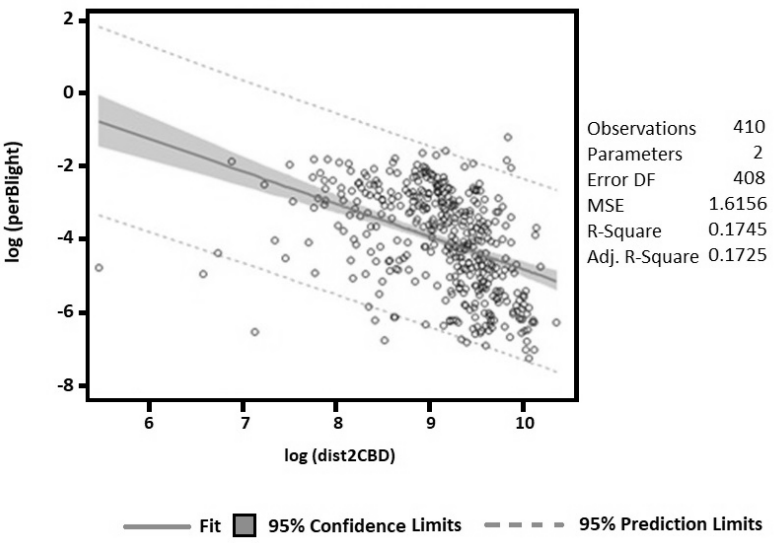

Fig. 8 Fitted plots of predicted variable (prcblight) and independent predictors in bivariate regressions (shannon index, medinc, and cbdmet)

The regression of distance to CBD (as an independent variable) and blighted properties' area percentage (as a dependent variable) for block groups in Memphis and Shelby County, 2010 by OLS method for robust fitting is a log-linear function (Fig. 8c). See also Fig. 9. In Model 3 (equation 12 ), the estimated $\beta_{1}=-0.911$, it means that a $10 \%$ increase in distance to the CBD (measured in meters) would lead to a $9.1 \%$ decrease in percent of the blighted area within a Census block group. 


\section{Sciendo}

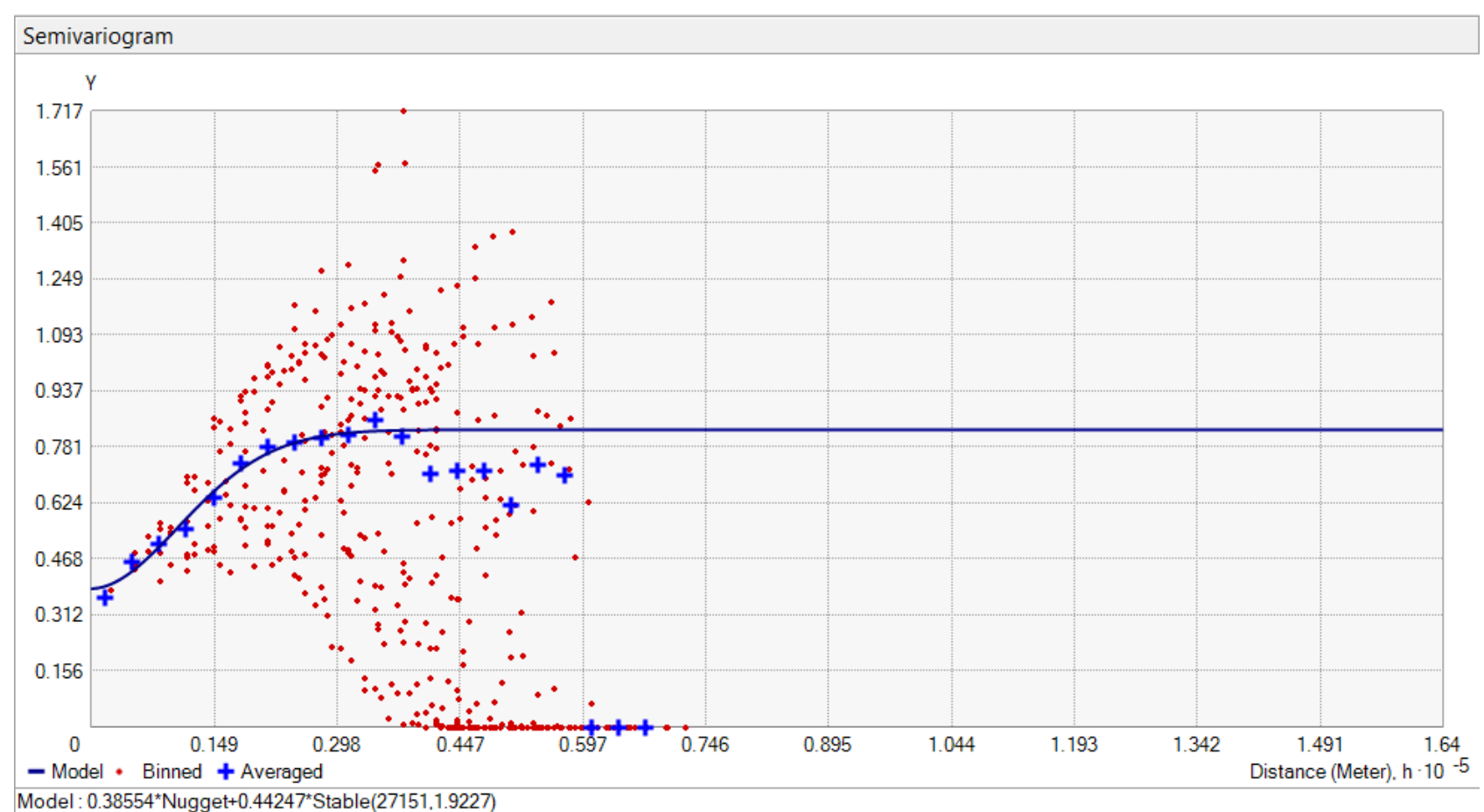

Fig. 9 A semivariogram describing the spatial continuity of blighted property. It uses the 1-km lag distances between pairs of points at which the semivariogram is calculated. Sample locations, the percentage of blighted properties, at distances closer than the range are spatially autocorrelated while locations farther apart than the range are not. The results are as expected for the percent blight variable, which are related to still other socio-spatial variables fitted in the regression

It turns out, the universally-held distance-decay phenomena include blight. The share of blighted properties in census block group decays log-linearly with distance from the city center (Fig. 8c). Regression modelling between percentage of blighted area (as a dependent variable) and three independent variables (Shannon index, median income, and distance to the CBD) conducted separately for block groups in Memphis Shelby County, 2010, resulted in the best fit for Model $2\left(R^{2}=0.04 ; 0.31\right.$, and 0.17, respectively).

We set out to determine whether several factors taken together make a difference in the incidence of blight. For this statistical purpose, we used stepwise multiple regression modeling. Model 4 (equations 13 to 15) examines the link between blight, Shannon relative index, and distance to CBD. The best fit was received by using level-level modelling.

The level-level regression specification for Model 4 is in the form:

$$
\begin{aligned}
y= & \beta_{0}+\beta_{1} x_{1}+\beta_{2} x_{2}+e \\
\text { prcblight }= & \beta_{0}+\beta_{1} \cdot(\text { Shannon Index }) \\
& +\beta_{2} \cdot(\text { Distance to the } C B D) \\
& +e
\end{aligned}
$$

Plugging in the estimates from the Model 4, we obtain:

$$
\begin{aligned}
\text { prcblight }= & 0.054+0.015 \cdot(\text { Shannon Index }) \\
& -0.00000247 \cdot(\text { Distance to the CBD }) \\
& +e
\end{aligned}
$$$$
(\mathrm{F}=107.73 * * * ; \mathrm{R}-\mathrm{Square}=0.269 ; \mathrm{N}=588)
$$$$
\text { (*0.05; ** } 0.01 ; * * * 0.001)
$$

Model 5 (equation 16) examines how blight is related to Shannon relative index, and income, while Model 6 (equation 17) examines the link between blight, Shannon relative index, distance to CBD, and income, and finally, Model 7 (equation 18) examines the impact of distance to CBD, and income on blight. For model 5, 6, and 7, a log-linear function was applied to get a better fit. Similarly, we can write the estimated equations for the Models 5, 6, and 7 as follows:

$$
\begin{aligned}
\operatorname{prcblight}= & e^{12.56+0.57 \cdot \log _{e}(\text { Shannon })} \\
& e^{-1.634 \cdot \log _{e}(\text { median income })+e}
\end{aligned}
$$

$\left(\mathrm{F}=90.26^{* * *} ; \mathrm{R}\right.$-Square $\left.=0.323 ; \mathrm{N}=588\right)$ 


$$
\begin{aligned}
\text { prcblight }= & e^{15.14+0.36 \cdot \log _{e}(\text { ShannonIndex })} \\
& e^{-0.57 \cdot \log _{e}(\text { Distance to } C B D)} \\
& e^{-1.38 \cdot \log _{e}(\text { median income })+e} \\
\text { prcblight }= & e^{0.054+0.015 \cdot \log _{e}(\text { Shannon })} \\
& e^{+00000247 \cdot \log _{e}(\text { Distance to } C B D)} \\
& e^{-0.00000247 \cdot \log _{e}(\text { median income })+e}
\end{aligned}
$$

(17a: $\left.\mathrm{F}=77.87^{* * *} ; \mathrm{R}-\mathrm{Square}=0.382 ; \mathrm{N}=588\right)$

$$
\begin{aligned}
\text { prcblight }= & e^{15.67-0.573 \cdot \log _{e}(\text { Distance to } C B D)} \\
& e^{-1.435 \cdot \log _{e}(\text { median income })+e}
\end{aligned}
$$

$\left(\mathrm{F}=120.99^{* * *} ; \mathrm{R}-\mathrm{Square}=0.373 ; \mathrm{N}=588\right)$

Multiple regression modelling between blighted area (as a dependent variable) and three independent variables (Shannon index, median income, and distance to $\mathrm{CBD}$ ) resulted in the best fit for Model $6\left(\mathrm{R}^{2}=0.38\right)$, while Models 4, 5, and 7 have lower values $\left(\mathrm{R}^{2}=0.27 ; 0.32\right.$, and 0.37 , respectively).

The signs are consistent in all models. Blight increases as distance to the CBD decreases, while income and Shannon index increase in value, as expected. Income and distance impact blight in a statistically significant way, while the effect of land use mix remains significant at 0.01 level after income is added into a model (Model 5, equation 16). However, the effect of land use mix (Shannon index) loses significance in Model 4 (equations 13 to 15) after distance is included, and in Model 6 (equation 17) with distance and income added in the model.

\section{Discussion and Conclusion}

Shannon entropy is regarded as a robust indicator of the magnitude of the sprawling metropolis. However, calculated to reflect the metropolitan region's sprawl as a whole, entropy masks the morphology of land cover and land use consequential to urban expansion within the city-region. We set out to determine what happens to the spatial structure of land cover and land use granularly with standard, census-defined block groups when a city spreads outward. The block-groups that determine census tracts, furthermore, approximate the neighborhood scale, a fundamental building block of the metropolitan-wide comprehensive planning. Entropy's normalized property (0-1) permits statistical analysis of spatial relationships with similarly ratio-scaled variables that are rarely explored in the literature of application of entropy in the measurement of urban sprawl. We set out to fill this void through investigation of the connections among entropy (an indicator of sprawl), household income (an indicator of regional inequality and blight), land use mix (an indicator of the concentration and dispersion of land use and land cover), and distance to CBD, a commonly used indicator of urban expansion.

Among the variables are blight and sprawl for which we determined a statistically significant relationship. We observed the correlation of urban blight on sprawl. This finding lends credence to theoretical discussion of sprawl as a driver of urban decay and regional inequality, characterized by blight (Calthorpe \& Fulton 2001; Brueckner \& Helsley 2011; Hortas-Rico 2015; Mock 2017). The Chicago school of urban sociology's seminal, observational mapping that theorized the outward growth of the city by a set of concentric zones, and the discussion of blighted areas linked to that growth is the precedent (Burgess 1925; Park et al. 1925; see also Hoyt 1939). We observe the decay of blight with distance from the city center.

The preliminary estimation of the relationships among variables noted above revealed multicollinearity. For that reason, we did variable selection with stepwise regressions estimation, Models $1-3$, Models $4-7$. The best fit is given by multiple regression Model 6 (equation 17), relating blight to Shannon index, median income, and distance to CBD. Bivariate scatter plots indicated nonlinearity. Thus, we used log transformation of the dependent and independent variables used in regression models including exponential functional form, shown in Fig. 8.

Arguably, sprawl is inherently a dynamical phenomenon-time as well as space figure prominently in an investigation of urban sprawl. Blockgroup land cover pixel and land use parcel data enabled mapping of transitions with the change in entropy values (subsection 2.1). We show built-up entropy change, from 2001-2011 (Fig. 4, and Table 1). Our statistical analyses of the relationships among blight, sprawl (entropy), income, land use (mix) and distance to CBD are cross-sectional (block group-level) rather than longitudinal. However, we make inferences about the dynamics of the values of the parameters, specifically with elasticity of blight with respect to a change in entropy (sprawl) (see equation 10). 
A logical extension of our study includes an examination of the change in entropy (equation 4), instead of entropy itself, used in the regressions with concomitant change in the values of the independent socio-spatial variables, like land-use mix, and income to capture the relational dynamics of sprawl and blight. The span of time is implied by the land cover and land use transitions, reported above (Fig. 4). As well as income, still other readily available socio-economic census block-group data-racial composition, ethnicity, age and employment status-plausibly extend the scope of investigation. An expansive investigation of the dynamics of the relations among the socio-spatial variables logically includes tests of spatial autocorrelation, including Moran (see semivariogram, Fig. 9).

We have also observed a close relationship between the Shannon index of sprawl and Simpson index of land use diversity. Land cover and land use mix and transitions should be interpreted carefully in determination of sprawl and blight. To aid in the planning of the neighborhood of new urbanism, which is defined by $1 / 4$ mile pedestrian shed, even a higher resolution of the built-up areas is required, not merely defined by one-mile square grid spanning entire urbanized area but a one-quarter of that grid, or 160 acres. A one-quarter mile grid overlay on block-groups aids in an analysis of urban form. The land-use mix and transitions of the builtup areas from low to high concentration or dispersion as indicated by entropy and diversity indices are thus interpreted in combination with other morphological factors including contiguity, density, walkability, and accessibility at an even higher level of granularity and resolution than the block-group scale. Exploration of the correlations of the factors that analytically determine the morphology of the new urbanism neighborhood remains a plausible next step in a future investigation. Our block-group level mapping with (Shannon) entropy and (Simpsons) diversity indicators are initial observations toward an even finer-level of resolution that reveals the morphology of the built-form and its organizational features. Thus, our block-group level analysis is a precursor to an even more refined morphological investigation. That morphology is not scale-invariant, just as measurement of urban from features cautioned above by MAUP. Careful consideration reveals whether or not the builtup area characterized by land-use mix, density, proximity, and accessibility approximates desirable features of an urbanism that reflects the pillars of smart growth or resembles sprawl (see smart growth network https://www.epa.gov/smartgrowth/smart-growth-network).
The City of Memphis and Shelby County have an approximately similar land cover for 2001, 2006, and 2011, judging by relative Shannon index values of land cover. However, the index value is consistently higher in the county $(0.21)$, indicating a greater sprawl compared to the city (0.17) for the same periods, as expected. If entropy index indicates the morphology of urban development, density, and consumption of land indicate the magnitude of the demand for land relative to population. From 2001 to 2011, the City lost population (-5.22\%), compared to the County's gain (3.93\%). Between 2001 to 2011, the City's and County's developed areas both increased, 3.26\% and $8.26 \%$, respectively. Both city and county declined in density. However, population density declined more in the city, $-8.22 \%$ (from 12.63 to 11.59 persons per hectare) compared to the county $-4.65 \%$, (from 10.22 to 9.75 persons/ha). The closest city with densities approximately similar to Memphis and Shelby County is Houston (for a global density comparison of forty-nine cities, see Bertaud 2004). Furthermore, the per capita consumption of land (m2/pop) decreases from 2001 level to 2011. For Shelby County, population density remains almost unchanged from 2006 (9.80) to 2011 (9.75). Notwithstanding the various assumptions used in defining built-up areas, we find significantly higher per capita land consumption (sq. meters/person) for 2001 in the City of Memphis (792) and Shelby County (978), compared to Washington D.C. (480) and Portland OR (120), reported in Calthorpe and Fulton (2001); see also Masek et al.(2000). We defined built-up as all land uses including impervious areas, roads and airport while excluding planted/agricultural lands, forests, wetlands and water bodies, shrub, herbaceous, barren and any unused lands.

Finally, regarding policy implications, we begin with observation of a decade worth of land cover transitions in the city and county (2000-2011), which indicates the conversion of a significant magnitude of natural land cover to built-up areas (urban development). The city administration is currently examining the policy on extension of sewer service to the county. Sewers and roads are among main "drivers" of urban growth, commonly in the form of a chaotic sprawl particularly in the absence of a comprehensive plan that is coupled with zoning regulations, or imposition of urban growth (service) boundary (Kelly, 2010). The public demand for local government services dealing with competing priorities including inner city blight remediation, among the consequences of sprawl, are the impetus for a more efficient supply of infrastructure 
with smarter urban growth particularly in the face of budget constraints.

While the urban-land use pattern is characterized by more or less sprawl, concomitantly it is also desirable to examine if the land use is more or less diverse, which we determined by coupling Shannon entropy and Simpson diversity indices. The policy implications are in the domains of planning and zoning regulation of land-use "mix" as well as "diversity" toward a sustainable urban form. As well, the comparison of the 2001-2011 land cover conversion with another decade up to the current period (2021) potentially informs if the change from planted/cultivated to "developed" or built-up still remains as the largest proportions of land conversions. Noteworthy is the impact, if any, of the 2008 real estate crisis with foreclosures on the land conversions determined in a future investigation.

The undesirable consequences of urban sprawl are noted in the urban studies literature. Among them are blight with the city's outward expansion, entrapping the low-income residents, with limited regional mobility and access to employment opportunities at the city's edge, in the inner city. We observed that blight increases with sprawl. Blight decays with distance from the city center. And as (block group per capita) income increases, blight decreases. Planning policy implications with a blight remediation strategy that is metropolitanwide, spatially targeted, and also mindful of the differentiated (block-level) pattern of urban sprawl suggest areas of further investigation.

\section{References}

Babcock H (2008) The National Environmental Policy Act in the urban environment: Oxymoron or a useful tool to combat the destruction of neighborhoods and urban sprawl? Journal of Environmental Law \& Litigation 23(1): 1-33.

Banai R, DePriest T (2014) Urban sprawl: Definitions, data, methods of measurement, and environmental consequences. Journal of Sustainability Education 7: 12.

Barker LE, Shaw KM (2015) Best (but oft-forgotten) practices: checking assumptions concerning regression residuals. The American Journal of Clinical Nutrition, 102(3): 533-539.

Batty M (1972) Entropy and spatial geometry. Area 4: 230-236.

Baum-Snow N (2007). Did highways cause suburbanization? The Quarterly Journal of Economics 122(2): 775-805.

Bhatta B, Saraswati S, Bandyopadhyay D (2010) Urban sprawl measurement from remote sensing data Applied Geography 30: 731-740.

Bereitschaft B, Debbage K (2014) Regional variations in urban fragmentation among U.S. metropolitan and megapolitan areas. Applied Spatial Analysis and Policy 7(2): 119-147.
Bertaud A (2004) The spatial organization of cities: Deliberate outcome or unforeseen consequence. World Development Report. The World Bank, Washington D.C.

Bluff City Snapshot survey (2016). The Department of Neighborhood Improvement, Division of Public Works, City of Memphis, TN, 2016. (Bluff City Snapshot conducted a twelve-week parcel survey in the last months of 2015, assessing the condition of land including industrial, residential and vacant lots).

Bourne L (2001) The urban sprawl debate: Myths, realities and hidden agendas. Plan Canada, 41(4), 26-30.

Brueckner JK, Helsley RW (2011) Sprawl and blight. Journal of Urban Economics 69(2): 205-213.

Burgess EW (1925) The growth of the city. In: Park RE, Burgess EW, McKenzie RD (eds) The city. University of Chicago Press, Chicago.

Calthorpe P (1993) The next American metropolis ecology, community, and the American dream. Princeton Architectural Press, New York. Available at: <https://www.scirp.org/(S(i43dyn45teexjx455qlt3d2q))/reference/ReferencesPapers.aspx?ReferenceID $=1570938>$

Calthorpe P, Fulton W (2001) The regional city: Planning for the end of sprawl. Island Press, Washington, D.C.

Ciscel DH (2000) Urban sprawl, urban promise, A case study of Memphis, Tennessee.

Ciscel DH (2001) The economics of urban sprawl: Inefficiency as a core feature of metropolitan growth. Journal of Economic Issues 35(2): 405-413.

Clark TA (2013) Metropolitan density, energy efficiency and carbon emissions: Multi-attribute tradeoffs and their policy implications. Energy Policy 53: 413-428.

Das S, Angadi DP (2020) Assessment of urban sprawl using landscape metrics and Shannon's entropy model approach in town level of Barrackpore sub-divisional region, India. Modeling Earth Systems and Environment 7: 1071-1095.

Duany A, Plater-Zyberk E, Speck J (2000). Suburban nation The rise of sprawl and the decline of the American dream. North Point Press, New York.

Duncan DT, Tamura K, Regan SD, Athens J, Elbel B, Meline J, Chaix B (2017) Quantifying spatial misclassification in exposure to noise complaints among low-Income housing residents across New York city neighborhoods: A Global Positioning System (GPS) study. Annals of Epidemiology 27(1): 67-75.

Effat HA, El Shobaky, MA (2015) Modeling and mapping of urban sprawl pattern in Cairo using multi-temporal Landsat images, and Shannon's Entropy. Advances in Remote Sensing 4: 303-318

Ewing R, Pendall R, Chen D (2003) Measuring sprawl and its transportation impacts. Transportation Research Record 1831: 175-183.

Ewing R, Hamidi S (2014) Smart growth America: Measuring sprawl 2014. Available at: <http://gis.cancer.gov/tools/urbansprawl> (accessed April 25, 2014)

Field AP (2009) Discovering statistics using SPSS: and sex and drugs and rock ' $n$ ' roll (3rd edition). Sage, London.

Goodman AC (1977) A Comparison of block group and census tract data in a hedonic housing price model. Land Economics 53(4): 483-487.

Hasse J, Lathrop R (2003) Land resource impact indicators of urban sprawl. Applied Geography 23: 159-175.

Gouda AA, Hosseini M, Masoumi HE (2016) The status of urban and suburban sprawl in Egypt and Iran. GeoScape 10(1): 1-15. 


\section{sciendo}

Hecht R, Herold H, Behnisch M, Jehling M (2019) Mapping longterm dynamics of population and dwellings based on a multitemporal analysis of urban morphologies. International Joural of Geo-Information 8: 2.

Hoyt H (1939) The structure and growth of residential neighborhoods in American cities. Federal Housing Administration, Washington, D.C.

Jargowsky PA (2011) Urban poverty, economic segregation, and urban policy. In: Brooks N, Donaghy K, Knaap G (eds) Oxford handbook of urban economics and planning. Oxford University Press, New York.

Galster G et al. (2000) Wrestling sprawl to the ground: Defining and measuring an elusive concept. Housing Policy Debate 12 (4): 681-717

Hortas-Rico M (2015) Sprawl, blight and the role of urban containment policies: Evidence from US Cities. SSRN Electronic Journal 55(2): 298-323.

Iceland J, Steinmetz E (2003) The effects of using census block groups instead of census tracts when examining residential housing patterns. U.S. Census Bureau Working Paper. Available at: <https://www.census.gov/hhes/www/housing/resseg/pdf/unit_of_analysis.pdf $>$

Katz P ed. (1994) The new urbanism: toward an architecture of community. McGraw-Hill, New York.

Kelly E (2010) Community planning. Island Press, Washington.

Laidley T (2016) Measuring sprawl: A new index, recent trends, and future research. Urban Affairs Review 52(1): 66-97.

Liu L, Peng Z, Wu H, Jiao H, Yu Y, Zhao J (2018) Fast identification of urban sprawl based on K-means clustering with population density and local spatial entropy. Sustainability 10(8).

Lopez R, Hynes HP (2003) Sprawl in the 1990s: Measurement, distribution, and trends. Urban Affairs Review 38(3): 325-355.

Lopez R (2014) Urban sprawl in the United States: 1970-2010. Cities and the Environment (CATE), 7(1). Available at: <https://digitalcommons.lmu.edu/cate/vol7/iss1/7>

Masek JG, Lindsay FE, Goward SN (2000) Dynamics of urban growth in the Washington DC metropolitan area, 1973-1996, from Landsat observations. International Journal of Remote Sensing, 21(18): 3473-3486.

Mock B (2017) The meaning of blight. CITYLAB. Available at: <https://www.bloomberg.com/news/articles/2017-02 16/why-we-talk-about-urban-blight>

Morris, E. K., Caruso T., Buscot F. (2014) Choosing and using diversity indices: insights for ecological applications from the German Biodiversity Exploratories. Ecology and Evolution 4,18: 3514-3524.

Musakwa W. and A. van Nieker.(2014) Monitoring urban sprawl and sustainable urban development Using the Moran Index: A case study of Stellenbosch, South Africa. International Journal of Applied Geospatial Research, 5(3), 1-20.

Multi-Resolution Land Characteristics Consortium (MRLC), for land cover classification. Available at: <https://www.mrlc.gov>

Nasser H, Overberg P (2001) What you don't know about sprawl. Controlling development a big concern, but analysis has unexpected findings. USA Today, $1 \mathrm{a}$.

National Land Cover Data (NLCD) Available at: <http://www.mrlc.gov>
Nazarnia N, Harding C, Jaeger JA (2019) How suitable is entropy as a measure of urban sprawl? Landscape and Urban Planning 184: $32-43$

Openshaw S (1984) The modifiable areal unit problem. CATMOG 38. GeoBooks, Norwich.

Papas MA, Alberg AJ, Ewing R, Helzlsour KJ, Gary TL, Klassen AC (2007) The built environment and obesity: a review of the evidence. Epidemiologic Reviews, 29(1): 129-143.

Park, RE, Burgess EW, McKenzie RD eds. (1925) The city: Suggestions for investigation of human behavior in the Urban Environment. University of Chicago Press, Chicago.

Perry CA (1929) The neighborhood unit: a scheme of arrangement for the family-life community. Regional study of New York and its environs, VII, Neighborhood and Community Planning, Monograph One 2-140. Regional Plan of New York and its Environs, New York.

Plexida S, Sfougaris A, Papadopoulos N (2012) Quantifying beetle and bird diversity in a Mediterranean mountain agro-ecosystem. Israel Journal of Ecology and Evolution 58(1): 1-25.

Ragusett JM (2016) Black residential segregation in the era of urban sprawl. The Review of Black Political Economy 43(3-4): 253-272.

Rahman MT (2016a) Detection of land use/land cover changes and urban sprawl in Al-Khobar, Saudi Arabia: An analysis of multi-temporal remote sensing data. International Journal of Geo-Information 5(2): 15.

Rahman MT (2016b) Land use and land cover changes and Yrban Sprawl in Riadh, Saudi Arabia: An analysis using multi-temporal Landsat data and Shannon's Entropy index. The International Archives of the Photogrammetry, Remote Sensing and Spatial Information Sciences, Volume XLI-B8, XXIII ISPRS Congress, 12-19 July 2016, pp. 1017-1021.

Ross CL, Leigh NG (2000) Planning urban revitalization and inner city: An exploration of structural racism. Journal of Planning Literature 14(3): 367-380.

Roth DS, Perfecto I, Rathcke B (1994) The effects of management systems on ground-foraging ant diversity in Costa Rica Author Ecological Applications 4(3): 423-436.

Salvati L, Carducci M (2014) Urban growth and land-use structure in two Mediterranean Regions: An exploratory spatial data analysis. Sage Open 4(4).

Tewolde MG, Cabral P (2011) Urban sprawl analysis and modeling in Asmara, Eritrea. Remote Sensing 3: 2148-2165.

Theil H (1967) Economics and information theory, NorthHolland, Amsterdam.

Thomas RW (1981) Information statistics in Geography. GeoAbstracts, University of East Anglia, Norwich.

Tuomisto $H$ (2010) A consistent terminology for quantifying species diversity. Oecologia 164: 853-860.

vom Hofe R, Parent O, Grabill M (2019) What to do with vacant and abandoned residential structures? The effects of teardowns and rehabilitations on nearby properties, Journal of Regional Science 59: 228-249.

Yeh A, Lee X (2001) Measurement and monitoring urban sprawl in a rapidly growing region using entropy. Photogrammetric Engineering and Remote Sensing 67: 83-89. 